\title{
O cuidado à saúde de pessoas com albinismo: uma dimensão da produção da vida na diferença
}

I ${ }^{1}$ Nereida Lúcia Palko dos Santos, ${ }^{2}$ Renata Meneses Magalhães Pereira,

${ }^{3}$ Marlea Chagas Moreira, ${ }^{4}$ Ana Lúcia Abrahão da Silva I

Resumo: O cuidado à saúde das pessoas com albinismo perpassa a invisibilidade social do grupo populacional, o acesso à informação e aos serviços de saúde, a integralidade do cuidado e a multiplicidade na produção da vida. O objetivo do estudo é discutir o cuidado à saúde de pessoas com albinismo e familiares. Estudo descritivo com abordagem qualitativa, desenvolvido no Instituto Benjamin Constant (IBC). A coleta dos dados ocorreu entre abril e maio de 2012, utilizando a entrevista individual semiestruturada com dez participantes, pessoas com albinismo / familiares, sendo: dois alunos do IBC, seis mães, uma avó e uma ex-aluna usuária do serviço de oftalmologia. Destacamos na intersetorialidade, a relação da saúde com a educação e a seguridade social. Há carência de formulação e efetivação das políticas sociais, dispositivos normativos, como possibilidade de superação da invisibilidade social e da garantia do direito à saúde. A vida das pessoas com albinismo extravasa a deficiência e a diferença, e demanda a efetivação de dispositivos normativos, processos singulares e subjetivos para a produção do cuidado no cotidiano das práticas em saúde. Mais que saberes dados, exige escuta, relações horizontais e coprodutivas para o cuidado em saúde.

> Palavras-chave: albinismo; pessoas com deficiência; assistência à saúde.

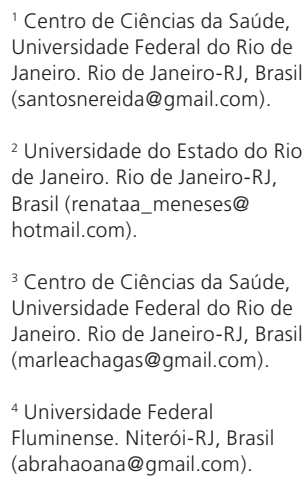

1 Centro de Ciências da Saúde, Universidade Federal do Rio de Janeiro. Rio de Janeiro-RJ, Brasil (santosnereida@gmail.com).

${ }^{2}$ Universidade do Estado do Rio de Janeiro. Rio de Janeiro-RJ, Brasil (renataa_meneses@ hotmail.com)

${ }^{3}$ Centro de Ciências da Saúde, Universidade Federal do Rio de Janeiro. Rio de Janeiro-RJ, Brasil (marleachagas@gmail.com).

${ }^{4}$ Universidade Federal Fluminense. Niterói-RJ, Brasil (abrahaoana@gmail.com).

Recebido em: 15/03/2016 Aprovado em: 25/09/2016 


\section{Introdução}

O albinismo é uma condição genética classificada no CID-10 (Classificação Internacional de Doenças) na categoria dos distúrbios metabólicos, código E70.3 (CENTRO BRASILEIRO DE CLASSIFICAÇÃO DE DOENÇAS, 2008). Nesta há a redução ou ausência do pigmento melanina, devido a ausência ou defeito da enzima tirosinase. No albinismo, a função de barreira natural aos raios ultravioleta (UV) da melanina está comprometida, contribuindo para que as pessoas com albinismo estejam mais vulneráveis a queimaduras solares, lesões de pele e câncer (MOREIRA, 2013).

Os portadores de albinismo, em sua maioria, possuem visão subnormal (CID10 H54.2), fotofobia (CID-10 H53.1), nistagmo (CID-10 H55), entre outras condições visuais permanentes a serem manejadas na produção da vida. Destas, a visão subnormal é remetida à condição de deficiência visual.

Entre as diferenças físicas, as alterações visuais, as restrições à exposição solar, a adaptação social e emocional, o cotidiano das pessoas com albinismo é perpassado pela vulnerabilidade a problemas e danos à saúde (BÍSCARO, 2012) que incluem a desigualdade no acesso ao direito à saúde, em parte, pela formulação de ofertas no sistema de saúde e do cuidado.

A oferta de atenção à saúde estrutura-se a partir de programas de saúde planejados pelas diferentes esferas de governo que levam em conta a dimensão epidemiológica do adoecimento, organizando os serviços na lógica da doença ou dos grupos em maior risco de contraí-la. A lógica calcada na dimensão epidemiológica é limitante às pessoas com albinismo por sua invisibilidade social, pelo não reconhecimento público deste grupo populacional, como por sua existência, tornando necessário transcender a captura de rótulos ou identidades limitadas às doenças (SOUZA, 2013), uma dimensão do cuidado mais alinhada às vidas singulares, mais ampliada ao uso de entidades nosológicas que procuram organizar as existências em parâmetros clínicos e/ou de classificação para registrar perfis úteis da funcionalidade, incapacidade e saúde supostamente representativos de uma neutralidade científica que reduz pessoas às doenças, deficiências, rótulos estigmatizantes, rótulos que codificam uma passividade dada como irreversível e genérica (ZAMBRONI-DE-SOUZA, 2006).

A lógica de organização do cuidado a grupos populacionais biomedicamente estabelecidos tem dado o contorno deste campo de produção, aproximando, 
por conta da visão subnormal, as pessoas com albinismo às construções sociais e de saúde comumente atribuídas às pessoas com deficiência. Como efeito, há a invisibilidade das pessoas com albinismo que se tornam visíveis e reconhecidas quando rotuladas como deficientes, por conta da visão subnormal; ou do desenvolvimento do câncer de pele, no lugar no qual a prevenção em saúde não mais surte efeitos diante do risco do adoecimento. A visibilidade das pessoas com albinismo precisa existir em todos os pontos de atenção, ser uma agenda transversal no Sistema Único de Saúde (SUS), ser ampliada e singularizada no campo do cuidado, da existência.

No sentido exposto, o modelo teórico-conceitual da biomedicina como matriz discursiva para o cuidado torna-se um obstáculo epistemológico para a proposta da integralidade pautada nas ações conjuntas entre a equipe multiprofissional, trabalhadores de saúde e os usuários, incluindo uma perspectiva da intersetorialidade. Entre os níveis e esferas do poder público que se relacionam com a saúde (SANTOS, 2013), inclui uma articulação entre setores sociais diversos e, portanto, de saberes, poderes e vontades, envolvendo a população em todas as etapas de implantação das ações para uma autonomia que não desqualifica e não desconsidera a centralidade do papel do Estado na formulação de políticas públicas (AZEVEDO, 2012).

$\mathrm{Na}$ perspectiva da produção do cuidado à saúde da pessoa com albinismo, identificamos que este é um campo - diferença - que não recebe investimentos, que passa pela invisibilidade social. Por outro lado, há alguma visibilidade, quando atrelado às ofertas e produções no eixo da deficiência visual, recebendo investimentos de diferentes frentes de governo e sociais para a reabilitação, para dispositivos e serviços, e possui a formulação de diretrizes com possibilidade de também se desdobrarem no cotidiano das pessoas com albinismo, carecendo de arranjos que fortaleçam a produção do cuidado e do reconhecimento social, na inclusão em sentido ampliado; um campo em produção com matrizes que operam em uma provisoriedade discursiva, na saúde e nos direitos das pessoas com albinismo (FOUCAULT, 2000). Neste campo, uma vertente da inclusão está ancorada nos direitos, ainda sendo vistos como algo de que a sociedade se desincumbe, pressupondo que os direitos das pessoas com albinismo estejam assegurados por lei, num processo moroso e distante do cotidiano, submetidos a conjuntos discursivos socialmente dados, regimes de verdade (FOUCAULT, 2012) na dimensão dos direitos como parte moduladora e essencial no jogo social. 
Assim, no cenário do cuidado em saúde, há um processo de luta por direitos, por reconhecimento, que poderá ser compreendido como reações defensivas e identitárias, ou bioidentitárias, possivelmente forjadas sob um jogo de forças de regimes semióticos estigmatizantes, até geradores de preconceito e descriminação, como certa dimensão fundante da subjetividade e da cidadania, em uma forma de articulação de movimentos sociais à garantia de direitos (BRASIL, 2014), dentre os quais o direito à saúde. Neste sentido, o cuidado à pessoas com albinismo agrega dimensões da existência e da produção da vida, considerando a experiência do desrespeito social em ações que busquem relaçôes de reconhecimento mútuo, pela pretensão dos indivíduos ao reconhecimento intersubjetivo de sua identidade (HONNETH, 2003).

O estudo teve origem a partir das questôes do campo empírico, nos possibilitou aproximações com uma lacuna da produção do conhecimento sobre a saúde, a educação e o combate às desigualdades, em especial pelo prisma da equidade e da universalização dos direitos humanos (IPEA, 2014). Uma contribuição ao grupo populacional de pessoas com albinismo, invisível ao Censo Demográfico (IBGE, 2010) e ao Estado brasileiro, em uma luta por reconhecimento público de suas demandas sociais e do gozo pleno de direitos (HONNETH, 2003; SOUZA, 2012).

Este é o objetivo: discutir o cuidado à saúde de pessoas com albinismo e familiares, pretendendo-se que essa produção possa contribuir com os efeitos da pesquisa para a produção da vida, das necessidades de saúde para a visibilidade e o reconhecimento público em prol da garantia do direito à saúde.

\section{Metodologia}

Estudo descritivo com abordagem qualitativa, desenvolvido no Instituto Benjamin Constant (IBC), órgão público federal de administração direta do Ministério da Educação, centro de referência nacional para as questôes da deficiência visual, que possui uma escola, capacita profissionais da área da deficiência visual, assessora escolas e instituições, realiza consultas oftamológicas às pessoas a ele vinculadas, reabilita e produz material especializado. A pesquisa foi desenvolvida no IBC porque este concentra pessoas com albinismo, devido ao atendimento oftalmológico para a especificidade da visão subnormal na cidade do Rio de Janeiro. 
A coleta dos dados ocorreu nos meses de abril e maio de 2012, através da entrevista individual semiestruturada, gravada em dispositivo eletrônico MP3, com os dez sujeitos participantes do estudo. Destes, todos são usuários dos serviços prestados (educação e atendimento oftalmológico) pelo IBC. Dois estudantes, cinco mães e uma avó de crianças que estudam em sistema de internato ou externato; e uma usuária, ex-aluna, e sua mãe, que aguardavam pelo atendimento oftalmológico da primeira. Para análise do material discursivo, foi aplicada a técnica de análise de conteúdo temática (BARDIN, 2011), e assegurado o anonimato dos participantes com a adoção de cores para sua identificação no corpo do texto (CINZA, ROSA, AMARELO, AZUL, AZUL ESCURO, VERMELHO e BRANCO).

A escolha dos participantes ocorreu a partir do entendimento de que as questôes que envolvem a vida das pessoas com albinismo acometem não apenas a elas, mas seus familiares. Foram critérios de inclusão: ser uma pessoa com albinismo ou seu familiar, ter relação com a instituição para atendimento à saúde e/ou escolaridade. Foram critérios de exclusão: não ser uma pessoa com albinismo ou familiar dela, condição considerada necessária para discutir o cuidado à saúde a partir do olhar do usuário/familiar com albinismo.

O estudo foi aprovado pelo Comitê de Ética em Pesquisa da Escola de Enfermagem Anna Nery (EEAN), Hospital Escola São Francisco de Assis (HESFA), sob o protocolo número 086/2011.

\section{Resultados e análise dos dados}

Das dez entrevistas realizadas, duas foram com alunos do IBC; seis com mães, cinco mães de estudantes da instituição e uma que acompanhava a usuária entrevistada no ambulatório. A décima entrevistada foi da avó de uma das estudantes, sua responsável.

No momento do desenvolvimento do estudo, havia no instituto oito estudantes com albinismo. A totalidade, pessoalmente ou por meio de seus familiares, integrou o estudo. Destes, três são do sexo masculino e cinco do feminino. As idades estão compreendidas entre sete e 20 anos de idade: dois com 12 anos, e as demais com: 7, 8, 10, 13, 16, e 20 anos, respectivamente.

Dois estudantes são internos, moram na instituição de segunda até sexta-feira, e suas responsáveis foram entrevistadas no horário da saída na sexta-feira. As demais 
foram entrevistadas durante a espera dos responsáveis pelo término do turno escolar. A entrevista com os discentes ocorreu nos horários de intervalo das aulas.

As responsáveis e seus filhos transitam pela cidade em transporte público (vans, metrô, ônibus e trem), chegam pela manhã cedo no IBC para o turno matinal das aulas, passam o dia na instituição e regressam para os domicílios no final do dia, após o horário estendido. Como residem longe do IBC, incluindo outros municípios, passam o dia aguardando o período de escolaridade dos filhos nas dependências da instituição. Uma das mães conseguiu emprego na própria instituição, conciliando o trabalho com os turnos de ensino.

Uma das famílias das estudantes é composta por duas meninas com albinismo, uma delas estudante do IBC e a outra, à época, fora da idade escolar. Atualmente, ambas estudam na instituição.

A usuária de 33 anos que aguardava por atendimento no ambulatório, estava acompanhada por sua mãe, que refere precisar acompanhar a filha nas consultas devido aos acidentes ocorridos, associados à baixa visão e à dificuldade da filha em se locomover pela cidade, especialmente por ser proveniente de um município da Baixada Litorânea do Rio de Janeiro.

As narrativas transitam por diferentes esferas da vida das pessoas com albinismo e de seus familiares, perpassam suas articulações e produções de modos de viver, e dos modos de produção de saúde. O cuidado à saúde pode ser expresso sob as dimensões do acesso à informação e aos serviços de saúde, desde o nascimento do bebê, perpassando pela intersetorialidade, em acordo com a noção de integralidade do cuidado e da multiplicidade na produção da vida na composição das dimensões em tela. Nestas, destacamos a relação com a educação, no sentido do acesso à escolarização e à vida escolar como sistema social, e na articulação das políticas sociais, que visam ao desenvolvimento, equidade e acesso aos direitos sociais.

Tais dimensões estão pautadas na política de atenção à pessoa com deficiência formulada pela Coordenação-Geral de Saúde da Pessoa com Deficiência (CGSPD), responsável pela coordenação do eixo da saúde. Esta rede, no âmbito do SUS, pretende ampliar o acesso e qualificar o atendimento; promover a vinculação das pessoas com deficiência; garantir a articulação e a integração dos pontos de atenção das redes de saúde no território, qualificando o cuidado por meio do acolhimento e classificação de risco (BRASIL, 2012). Se por um lado 
representava um avanço que culmina com o lançamento do Programa Viver sem Limite (BRASIL, 2011) sob a ideia da inclusão a partir da diferença na produção de movimento e ocupação de espaços políticos nas redes (BRASIL, 2014); por outro, ainda é insuficiente para a composição e articulação de 15 frentes ministeriais para sua plenitude, e para efeitos na vida das pessoas com albinismo, para que não estejam rotuladas como deficientes, que habitam um não lugar diante das lógicas de encaixe ofertadas pelo sistema.

No tocante à produção da vida na diferença, esta se inicia no nascimento, com a ruptura da ideia da chegada do bebê "ideal” (BARBOSA, 2009), perpassando a ausência de informação e orientação sobre o albinismo de forma geral, e especificamente ao cuidado do bebê.

Eu tive um baque, porque ela era muito branca e meu marido mais escuro. Mas ela era muito parecida com ele. [...] não queria aceitá-la mas depois correu tudo bem. [...] veio me entregar e me entregaram logo a branca. [...] Mas quando me entregou eu falei, não, não é possível que é a minha filha. Meu marido também estranhou um pouco, mas ele viu que não tinha como ela ter sido trocada porque era muito parecida com ele. (CINZA).

Foi uma surpresa muito grande quando ela nasceu porque foi tudo muito novo pra mim e não tinha contato com ninguém com albinismo. Só me falaram que ela era branca demais, não falaram que ela tinha albinismo, não falaram nada. (ROSA)

Há uma convocatória capitalística que remete a uma certa "normalidade" de enquadramento aos modos de vida na diferença - uma produção naturalmente dada no cotidiano, com necessidades de acesso a escolas, saúde e bens e serviços.

A escolaridade e o acesso aos serviços de saúde, principalmente o das especialidades - dermatologia e oftalmologia trazem à cena a interrupção, insuficiência ou inexistência de fluxos no cuidado no empoderamento do usuário ao protagonismo de sua vida, impactando nas desigualdades sociais. Os participantes deste estudo, na sua maioria, criam manejos econômicos ao impacto da condição física e a adaptação na vida cotidiana, como a necessidade de aquisição regular de protetores solares, óculos com lentes filtrantes aos raios solares, medicamentos para o cuidado e manutenção da pele, entre outros.

A intersetorialidade possui forte relação entre a saúde e a atenção social; na segunda, os recursos frequentemente recorridos são o Benefíco de Prestação Continuada (BPC) e o Passe Livre, tanto em decorrência da deficiência visual, como pelo albinismo, com diferentes formas de manejo diante desta. A falta de informação, de conhecimento deste como um auxílio, ou mesmo como direito 
não acontece uniformemente, nem como uma informação que circule no espaço de convivência institucional (IBC). Outra questão relativa ao benefício social está relacionada ao transporte, que para 90\% dos participantes implica gastos com o usuário e um acompanhante em passagens municipais e intermunicipais para acessarem a instituição diariamente para a escolaridade e/ou regularmente para o acompanhamento oftalmológico.

Eu consegui (BPC e Passe Livre) antes dela entrar aqui (IBC). O médico dela que ajudou, dá um laudo pra fazer o passe. Não é difícil não. O beneficio eu consegui quando ela entrou aqui, mas eu não sabia que ela tinha direito. As pessoas que me disseram que ela tinha direito.[...](AMARELO)

Foi muito difícil, mas eu consegui (BPC), não pela cegueira, mas pelo albinismo, porque eu tenho câncer (de pele). Aqui só me encaminharam pra vale transporte. Protetor solar e benefício, nunca! Eu nem sabia que tinha direito, nem sabia. Hoje eu tenho passe com direito a acompanhante pela visão e pelo câncer. [...] O câncer ajudou em tudo, assim. Hoje eu ganho o LOAS (Lei Orgânica da Assistência Social, refere-se ao BPC) que é o benefício assistencial. [...] Pra conseguir as coisas, tem que ficar dizendo que tenho câncer, que sou deficiente visual, tem que contar toda uma história triste, de coitada. (AZUL)

A necessidade da proteção solar, uma tecnologia de cuidado, é tônica presente e indissociável da situação financeira, pois o alto custo dos protetores solares e de lentes filtrantes, e a necessidade de uso continuado desses produtos repercute no aspecto econômico e se juntam às questôes da esfera dos benefícios sociais.

O protetor solar eu consegui na justiça, é porque é muito caro, o $\mathrm{H}$ que ela usa é muito caro, então, até o benefício que ela ganha não ia dar, nem o que eu ganho não ia dar. [...] Ela (dermatologista) só passa remédios caros pra proteção da pele mesmo. E ela (a filha) agora tá dando muitas bolinhas com pus, eu nunca deixo virar ferida, não. [...] O protetor é uma bisnaguinha desse tamanho $(10 \mathrm{~cm})$, se eu passar como a doutora fala, fazendo uma segunda pele, não dá pra nada. Tá difícil pegar um ou dois, como é que vou passar nela toda? Não vai durar, e onde vou arrumar dinheiro pra comprar? [...] Já chegou a fazer ferida na pele, nas costas, mas eu insisto muito com ela. Eu já falei com ela, aquilo ali (lesão de outra pessoa conhecida na instituição) é um câncer, se você não se cuidar, pode ficar assim. É horrível!. (ROSA)

A escolarização é outra face fundamental em cena, pois é dispositivo de produção da vida cotidiana para as famílias, tanto por ser uma obrigatoriedade legal, como pela aposta na formação acadêmica como um local de saberes. A escola é o ambiente no qual a criança começa a fazer parte de um grupo maior, e seu relacionamento com outras crianças e professores ajuda a desenvolver seu autoconceito e sua autoestima (BARBOSA, 2009). 
Os estudantes do IBC participantes deste estudo têm uma trajetória de inserção na rede regular de ensino; por razões muito próximas, tiveram a necessidade de recorrer a um instituto especializado em educação de deficientes visuais para garantir o direito à escolaridade. As narrativas expressam o desprovimento de estrutura física adequada, de recursos materiais e humanos ao atendimento das especificidades demandadas.

Diferentemente das proposiçōes relativas à inclusão escolar, as narrativas são carregadas da necessidade de (in)formação dos professores para a compreensão a respeito da vida, dos cuidados à criança que vai além do papel de ensinar, da participação no processo de inserção dos alunos em escolas e turmas regulares, e da falta de material ampliado ou em relevo, ou em suporte digital, entre outros, de investimentos e ações tais como ampliação e otimização das bibliotecas, e adaptação estrutural quanto à iluminação das salas de aula (BARBOSA, 2009; BEZERRA, 2007).

[...] Estudou um ano no colégio particular que não deu certo e depois eu coloquei ela no Brizolão, que tinha a tal da inclusão né, que não adianta nada! Aí, eu trouxe ela pra cá.[...] Ela veio pro IBC em 2007.[...] (AMARELO)

Aqui está outro mundo, ela esta gostando demais, a auto-estima dela melhorou, ela já está encarando que ela é albina, até outro dia a moça falou assim: "-Nossa, você é muito branca!" Aí ela falou assim: “-Não, eu não sou branca, sou albina”. (ROSA)

Ele estudava em CG (bairro da Zona Oeste do Rio de Janeiro), numa escola particular. Ele não estudava direito, quase não conseguia acompanhar a turma, tinha muita dificuldade, porque na escola não era letra grande. (AZUL ESCURO)

Na dimensão da atenção à saúde, são destacadas as áreas de especialidade da dermatologia e da oftalmologia, não apenas pela necessidade de acompanhamento por profissionais com esta formação, como pela dificuldade em acessar esses profissionais para o acompanhamento continuado ao longo da vida. Em 2012, no período da realização das entrevistas, esta tinha uma dimensão significativa na rede de atenção à saúde do município e estado do Rio de Janeiro, pois, embora a cobertura na Atenção Básica tenha ampliado, e o sistema de regulação tenha sido estabelecido para o acesso às especialidades, no momento em tela, os participantes ainda se depararam com a invisibilidade das pessoas com albinismo e suas necessidades de atendimento, com fluxos não consolidados do sistema de regulação para a atenção nas áreas de especialidade, com gargalos e até com a falta da oferta de serviços e profissionais para a continuidade do cuidado. Neste 
contexto, está inclusa a desinformação, pois os usuários além de não acessarem a rede de atenção e as especialidades, também passam pelos serviços sem receberem orientação e informação acerca do albinismo e da baixa visão e das ofertas pautadas no sistema da saúde, na rede de atenção, impactando diretamente no cuidado e na produção da vida.

Até que com 7 anos, eu percebi que o desenvolvimento dela estava caindo muito, tudo que aprendeu ela tava regredindo e resolvi ir de novo no oftalmologista e aí essa já era diferente e falou que eu tinha que tratá-la em um hospital maior, e me explicou da baixa visão. Falou que eu tava piorando a visão dela, mas não foi culpa minha, só que eu não tive ninguém pra me orientar. [...] Quando eu tinha plano ela ia muito no dermatologista, e tratar também de umas pintinhas que nasceram nas costas, mas falam que é normal. [...] Todos os dermatologistas que fui foram no particular, no publico nenhum [...] Já tentei em vários lugares mas dizem que não tem vaga, que eu tenho que ficar ligando pra saber, e quando marca é pra muito longe. (ROSA)

Passei pelo HL, pelo HJ. Quando eu cheguei na L, que ele teve um tratamento mais especial, só que não tinha equipamentos adequados pra fazer o exame, aí me mandaram pra cá (IBC) e eu consegui.(VERMELHO)

Não tinha atendimento de nada, só conseguiu atendimento depois que começou a estudar aqui. [...] No começo das aulas faz o exame e eu mando fazer os óculos, particular (comprando). [...] Ela tem baixa visão, com dificuldade, mas ela lê, a claridade incomoda ela sim. Tive que fazer consulta particular de oftalmologista, porque quando eu levava ela lá no $\mathrm{HJ}$, eles não conseguiam fazer exame, porque o olho dela não ficava parado (nistagmo), ai eles diziam que não conseguiam. Tive que pagar particular pra fazer os exames. [...] O dermatologista que era dela sumiu no mapa, ela tratava com ele desde 1 ano e 2 meses. Tanto que a pele dela ta tão escamosa, que o creme dela só compra com receita. [...] Vou no médico perto da minha casa, mas é particular, trinta reais a consulta(AMARELO).

[...] faço tudo no PSF (Programa Saúde da Família - Atenção Básica), eles cuidam de tudo, de todas as áreas, lá em CF (Município da Baixada Litorânea / RJ) é muito boa a saúde, muito boa, em vista daqui. Eu não vou nem no posto para marcar, todo mundo sabe que eu tenho câncer, ai eu ligo e eles me encaixam em qualquer coisa. Eu precisei ter câncer pra ter o acesso fácil [...].(AZUL)

Uma dimensão da vida das pessoas participantes do estudo lida diretamente com a diferença que está na pele, na cara e de forma intensa repercurte nos modos de vida, na produção da existência, pois relaciona-se com a dimensão física de ser e estar no mundo. Uma necessidade de saúde que impacta objetiva e subjetivamente no modo de andar a vida e na construção do sujeito, com efeitos para além do autocuidado e da autonomia.

[...] Eu sou até um pouco teimosa, eu deveria andar com chapéu, de óculos escuros. Já pareço estranha aos olhos dos outros, vou chegar de chapéu e óculos escuros, roupa 
comprida, etc. vão pensar que eu sou o ET (extra terrestre), né? É porque, o albino quando ele chega, ele já cria um impacto, mesmo sem a gente querer, por mais que queira ser normal, a gente chama atenção. [...] Não só deficiente, deficiente visual albino. Você já viu albino trabalhando em alguma loja de roupa? Não, porque ele não tem aparência para isso. Já viu algum albino trabalhando em algum escritório, já viu? Nunca, porque a gente não tem aparência pra isso, eles não dão oportunidade nenhuma. Eu fiz técnico de informática e não consegui emprego, nem estágio eu consegui. [...] hoje em dia eu vendo roupa, e consegui o benefício do governo.(AZUL)

Da última vez foi ali na Central, fui comprar uma meia no camelô ali, foi o "verdadeiro negro". Meu Deus, quanta ignorância! Teve uma vez que uma mulher tava no HP, eu tava ali do lado de fora, e fui fazer um lanchinho, e fui com ela (neta com albinismo), pra ela comer o lanche, ai, veio uma mulher, que fez questão de sentar perto da gente, e começou a falar. “- Isso ai pega, não pega?”. Eu disse: “- Não, isso ai o quê?!" (BRANCO)

As pessoas com albinismo produzem suas vidas para além da deficiência e da diferença, produzem afetos, relações, trabalho e inclusão, fazem movimentos de extravasamento de limites impostos e de invenção cotidiana da vida, vazam com os fluxos normativos dos sistemas de saúde, educacional, de seguridade social e, no seu fazer / viver, inventam suas formas de existir, suas redes de existência, suas redes vivas (MERHY et al., 2014). Diante das necessidades, criam respostas, produzem as vidas.

É nesse espaço de força inventiva que vemos a potência do cuidado, não o cuidado institucionalizado no sentido reduzido à atenção biomédica/biologicista, ou seja, voltada ainda, predominantemente para o atendimento das necessidades biológicas, mas o cuidado que constrói com o usuário a partir do que este reconhece como suas necessidades, possível de ser ofertado e produzido em arranjos pactuados e compartilhados, multidisciplinares, intersetoriais. Este, em dupla face do limite e da potência deste estudo, pois na medida que nos apresenta a insuficiência de uma profissão ou disciplina para cuidar e atender às necessidades dos usuários, nos permite ampliar ofertas, pactuações e articulações que extravasam enquadramanetos tais como deficiência, diferença ou normalidade, pois traz para a cena a noção de que toda a vida vale a pena e do espaço possível de açôes, atos de cuidado em diferentes modalidades.

\section{Consideraçôes finais}

No cenário em tela, as pessoas com albinismo e seus familiares, em suas multiplicidades, onde a todo e qualquer instante pode ser subtraída desta uma 
determinada singularidade que continua em conexão com o conjunto, criam no campo do cuidado, nas singularidades dos sujeitos suas Redes Vivas (de saúde, de educação, de assistência social, de afetos, e tantas quantas possam ser vividas), redes de existências, constituindo certas formas éticas existenciais e certos modos de conduzir, por si, também a produção de cuidado, disputando o tempo inteiro com as outras diferentes lógicas de existir, em si (MERHY et al., 2014).

Conforme conseguem ter experiências, produzem agenciamentos, instauram uma rede rizomática não linear, por vezes, se apegando a diferença e à deficiência como formas de dialogar com forças instituídas e regras sociais enunciadas, tais como ter um CID, para justificar e nomear suas necessidades; outras, vivendo na potência da diferença a criação de mundos possíveis, dando fluxo às demandas por cuidado e acesso às tecnologias que melhor possam lhes atender para uma vida possível e independente. De outro modo, podemos dizer que as pessoas com albinismo são Redes Vivas de si próprias, estão o tempo inteiro produzindo movimentos, elaborando saberes, construindo e partilhando cuidados (MERHY et al., 2014).

Diante do limite que propostas normatizadas e investigações pontuais possuam diante da vida, podemos caminhar ao fechamento desta com a certeza de que a limitação deste estudo é a impossibilidade de capturar todas as dimensões do cuidado possíveis, pois a vida das pessoas com albinismo extravasa o albinismo em si mesmo, a deficiência e a diferença, porque a singularidade de cada sujeito exige mais que saberes dados, exige escuta, exige estar com o outro em relaçôes horizontais e coprodutivas.

Neste sentido, o cuidado é um acontecimento que se dá no encontro e na pactuação cotidiana de ofertas possíveis às necessidades de saúde (GOMES, 2014); entretanto, para sua efetivação, carecemos de avanços neste campo de produção, à luz da sua provisoriedade discursiva, com mecanismos de responsabilização pelas equipes, gestores públicos, operadoras de planos de saúde, e da operacionalização da integralidade do cuidado, da intersetorialidade que efetive a integração de diferentes setores que são saúde, viabilizando novos horizontes às práticas em produção.

Assim, para que esse processo alcance capilaridade, é importante que haja informação circulando nas diferentes esferas públicas de saúde, educação, prestação de serviços, com garantia de acesso às tecnologias que melhorem e 
prolonguem a vida, e a possibilidade de concretamente escolher os modos de andar

a vida, com autonomia, contribuindo ao cuidado de pessoas com albinismo. ${ }^{1}$

\section{Referências}

AZEVEDO, E.; PELICIONI, M. C. F.; WESTPHAL, M. F. Práticas intersetoriais nas políticas públicas de promoção de saúde. Physis: Revista de Saúde Coletiva. Rio de Janeiro, v. 22, n. 4, p. 1333-1356, 2012.

BARBOSA, M.A.M. et al. Care of disabled children: social support acessed by mothers. Rev Gauicha Enferm., Porto Alegre, v. 30, n. 3, p. 406-12, set. 2009.

BARDIN, L. Análise de Conteúdo. São Paulo: Ediçōes 70, 2011. 229 p.

BEZERRA, C.P.; PAGLIUCA, L.M.F. Visually-impaired adolescents' interpersonal relationships at school. Rev Gaúcha Enferm., Porto Alegre, v. 28, n. 3, p. 315-23, 2007.

BÍSCARO, R. R. Escolhi ser albino. São Carlos: EduFSCar, 2012.

BRASIL. Ministério da Saúde. Secretaria de Atenção à Saúde. Departamento de Ações Programáticas Estratégicas. Diálogo (bio)político sobre alguns desafios da construção da Rede de Cuidados à Saúde da Pessoa com Deficiência do SUS / Ministério da Saúde, Secretaria de Atenção à Saúde, Departamento de Açōes Programáticas Estratégicas. Brasília: Ministério da Saúde, 2014.

BRASIL. Portaria MS / GM no 793, de 24 de abril de 2012. Institui a Rede de Cuidado à Pessoa com Deficiência no âmbito do Sistema Único de Saúde. Ministério da Saúde, Gabinete do Ministro. Diário Oficial da União, Brasília; 24 abr 2012.

BRASIL. Presidência da República. Casa Civil. Subchefia para Assuntos Jurídicos. Decreto no7612, de 17 de novembro de 2011. Institui o Plano Nacional dos Direitos da Pessoa com Deficiência - Plano Viver sem Limite. Disponível em: http://www.planalto.gov.br/ ccivil_03/_Ato2011-2014/2011/Decreto/D7612.htm. Acesso em: 28 jun. 2013.

Centro Brasileiro de Classificação de Doenças. Centro Colaborador da OMS para a Classificação de Doenças em Português - Faculdade de Saúde Pública da Universidade de São Paulo/Organização Mundial de Saúde/Organização Pan-Americana de Saúde. CID-10. Classificação Estatística Internacional de Doenças e Problemas Relacionados à Saúde. Décima Revisão. Versão 2008. Volume I. disponível em: <http://www.datasus.gov.br/cid10/V2008/ WebHelp/cid10.htm>. Acessado em 02/03/2016.

FOUCAULT, M. As palavras e as coisas: uma arqueologia das ciências humanas. $8^{a}$ ed. São Paulo: Martins Fontes, 2000. 422 p.

FOUCAULT, M. Microfisica do Poder. 25a ed. Rio de Janeiro: Graal; 2012. 432 p.

GOMES, M.P.; MERHY, E.E. (Org.). Pesquisadores IN-MUNDO: um estudo da produção do acesso e barreira em saúde mental. Porto Alegre: Rede UNIDA, 2014. 176 p. 
HONNETH, A. Luta por Reconhecimento: a gramática moral dos conflitos sociais. Tradução de Luiz Repa. São Paulo: Editora 34, 2003. 296 p.

INSTITUTO BRASILEIRO DE GEOGRAFIA E ESTATÍSTICA. Censo Demográfico de 2010, Brasília, IBGE. Disponível em: < http://www.ibge.gov.br/home/estatistica/ populacao/censo2010/>. Acesso em: 07 mar. 2016.

INSTITUTO DE PESQUISA ECONÔMICA APLICADA E SECRETARIA DE PLANEJAMENTO E INVESTIMENTOS ESTRATÉGICOS (Coord.). Objetivos de Desenvolvimento do Milênio: Relatório Nacional de Acompanhamento. supervisão: Grupo Técnico para o acompanhamento dos ODM. - Brasília: Ipea: MP, SPI, 2014. 208 p. Disponível em: <http://www.pnud.org.br/Docs/5_RelatorioNacionalAcompanhamentoODM.pdf>. Acesso em: 07 mar. 2016.

MERHY, E.E. et al. Redes Vivas: multiplicidades girando as existências, sinais da rua. Implicações para a produção do cuidado e a produção do conhecimento em saúde. Divulgação em Saúde Para Debate., Rio de Janeiro, n. 52, p. 153-164, out. 2014.

MOREIRA, S.C. et al. Associação entre a suscetibilidade à exposição solar e a ocorrência de câncer de pele em albinos. Rev. Ciênc. Méd. Biol. Salvador, v. 12, n. 1, p. 70-74, jan./abr. 2013.

SANTOS, N. L. P. et al. Nursing care provided to blood donors - from the perspective of integral healthcare. Esc. Anna Nery. Rio de Janeiro, v. 17, n. 4, p. 661-667, 2013.

SOUZA, C. R.; BOTAZZO, C. Social construction of health demand. Physis: Revista de Saúde COletiva. Rio de Janeiro, v. 23, n. 2, p. 393-413, 2013.

SOUZA, J. A construção social da subcidadania: para uma sociologia política da modernidade periférica. 2a ed. Belo Horizonte: EdUFMG, 2012. 212 p.

ZAMBRONI-DE-SOUZA, P.C. Trabalho, organização e pessoas com transtornos mentais graves. Cadernos de Psicologia Social do Trabalho, v. 9, n. 1, p. 91-105, 2006.

\section{Nota}

${ }^{1}$ N.S.P. dos Santos foi responsável pela idealização, elaboração, desenho metodológico, desenvolvimento, análise e conclusão. R.M.M. Pereira responsabilizou-se pela elaboração, desenho metodológico, desenvolvimento, análise e conclusão. M.C. Moreira e A.L.A. da Silva realizaram a elaboração, desenho metodológico, análise e conclusão deste artigo. 


\section{Abstract}

Health care of persons with albinism: a dimension of life production in difference The healthcare of people with albinism goes beyond the social invisibility of this population group, access to information and health services, comprehensive care and multiplicity in life production. The aim is to discuss the health care of people with albinism and their family. Descriptive study with a qualitative approach was developed at Benjamin Constant Institute (IBC). Data collection took place between April and May of 2012, using semi-structured individual interviews with ten participants, people with albinism / family, as follows: two students of IBC, six mothers, a grandmother and a user of the ophthalmology service. Highlighting the intersectionality, health related education and social security. There is a lack of formulation and execution of social policies, regulatory requirements, as the possibility of overcoming social invisibility and ensuring the right to health. The lives of people with albinism goes beyond disability and difference and demand the fulfillment of regulatory requirements, unique and subjective processes for the production of care in daily health practices. More than data knowledge, they require listening, horizontal relations and co-production for health care.

> Keywords: albinism; disabled persons; delivery of health care. 